\title{
AIR BUBBLE STRATIGRAPHY OF LAKE ICE COVERS
}

\author{
(Abstract only)
}

\author{
by \\ Richard Heron \\ (Department of Geography, McMaster University, Hamilton, Ontario L8S 4K1, Canada)
}

\section{ABSTRACT}

Lake ice often has inclusions of air bubbles and their presence affects the thermal, mechanical, optical and other physical properties of the ice cover. Vertical variation in the characteristics of the bubbles suggests that their characteristics should be related to the rate of ice growth at the time of formation and therefore reflect past meteorological conditions.

The 1aboratory studies of Carte (1961) and Bari and Hallett (1974) demonstrated that the rate of ice growth affects the size, shape and distribution of bubbles and the porosity of the ice. Their results were generally supported by the field study of Gow and Langston (1977), but Swinzow (1966) found no relationship between bubble characteristics and the rate of ice growth.

Freeze-up and initial ice growth were monitored at Small Lake, Resolute, NWT, Canada, in 1979 to determine what diagnostic information might be obtained fron the inclusion stratigraphy of the ice cover. Additional samples were collected from five other lakes in the Resolute area, a shallow lake near Hamilton, Ontario, and two lakes near Huntsville, Ontario. Daily ice samples were removed from the ice cover of Smal1 Lake and the inclusion stratigraphy was mapped. A typical ice sample shows diurnal sequences of bubbly and bubble-free ice. The inclusion layers, 1 to 5 min thick, were formed near midday and were separated by 10 to $15 \mathrm{~min}$ of clear, bubblefree ice. All samples were missing at least one inclusion stratum. There was a wide variety of bubble types and sizes, and non-gaseous inclusions, believed to be algae, were noted in some of the bubble layers. The hourly rate of ice growth was calculated using a modified Stefan equation. No relationship between the bubble characteristics and the rate of ice growth was obtained. The influence of the algae and the absorption of solar radiation by the water are probably responsible for the diurnal cycle of bubble formation by influencing nucleation. The absorbed radiation will warm the water and decrease the amount of air that the water can dissolve, thus making more air available for bubble growth. The algae will also change the concentrations of dissolved gases and act as nucleating agents.

Cores taken from Small Lake in spring showed large cylindrical bubbles in the lower meter of the ice cover which had a thickness of $2.4 \mathrm{~m}$. An inverse relationship between porosity and rate of ice growth was observed for these bubbles.

Ice samples taken frow the other lakes in the Resolute area either showed no inclusions at all or exhibited fewer diurnal inclusion sequences. Using a general bubble stratigraphy obtained from Small Lake it is possible to correlate some inclusion layers in samples taken from lakes that are $15 \mathrm{~km}$ apart.

The samples from Hamilton also showed diurnal stratigraphic sequences except that the spacing between the bubble layers was more variable due to a larger range of daily growth rates. However, the two lakes near Huntsville had a detailed bubble stratigraphy, with little clear ice and no evidence of diurnal variation. The bubble layers in the ice from the two lakes could be easily matched, although they are $15 \mathrm{~km}$ apart.

This study shows that bubble layers formed in a growing ice cover may be used to reveal some aspects of the history of the growth of the ice cover, al though the applicability depends greatly on local conditions. Additional studies are required to understand the mechanisms by which air bubbles and algae are incorporated into lake ice.

\section{REFERENCES}

Bari S A, Hallett J 1974 Nucleation and growth of bubbles at an ice-water interface. Jourmal of Glaciology 13(69): 489-520

Carte AE 1961 Air bubbles in ice. Proceedings of the Physical Society (London) 77(495): 757-768

Gow A J, Langston D 1977 Growth history of lake ice in relation to its stratigraphic, crystalline and mechanical structure. CRREL Report 77-1

Swinzow G K 1966 Ice cover of an Arctic proglacial 1ake. CRREL Research Report 115 